\title{
Cultural Psychology: A Once and Future Discipline
}

By Michael Cole. Harvard University Press, 1996. 400 pages.

For the past thirty years, Michael Cole has been a prolific writer, researcher, and creative thinker in the field of developmental psychology. In Cultural Psychology: A Once and Future Discipline, he attempts to synthesize what he has learned and to set forth an approach to developmental psychology from an historical and cultural perspective. Hence, a culturally sensitive science of human development appears to be Cole's objective. He describes cultural psychology as "the study of culture's role in the mental life of human beings." His subtitle suggests that cultural psychology was a discipline which existed in former times and will exist again in the future. Cole argues in favor of what is known as a "second psychology," which moves beyond the confines of traditional and contemporary psychological thinking about how the human mind is understood. The former psychology, described as naturalistic, has focused on the familiar and more classical views. Such views evolved from our analysis of mental phenomena developed from ideas, sensations, reflexes, and experiences with sensorimotor connections. Alternately, the latter approach, "second psychology," looks at the higher mental processes formed by cultures. These include things such as languages, myths, and social practices within the individual's social context. The author reviews the evolution of thought through several contemporary thinkers who, in his view, have contributed the substance of a scientific, second psychology-oriented methodology necessary for a viable, efficacious cultural psychology. That is to say a psychology which is sensitive to social and cultural contexts. The context includes such things as language, rituals, and routines as they contribute to understanding people in terms of their interdependence, cooperation, and essential hurnanity. 


\section{Enduring Questions and Disputes}

Cole says, "to understand something it is important to know its history" (p. 4). The author explores how the relationship between culture and thinking was viewed and approached before psychology came into being; that is, he explores the prehistory of psychology. In Cole's view, cultural psychology was there, he says, "in the beginning" (p. 4). The topics of Chapter One include a discussion under the heading "In the Beginning," which presents historical evidence of "culture's becoming a self-conscious phenomenon which can be traced back to the Greek historian, Herodotus" (p. 8); a section called "Primitives and Children," which explores and discusses psychic unity, sociocultural evolution and comparisons of thinking adults in modern societies as compared to thinking people living in less developed societies; and a section called, "Biological Recapitulation Hypothesis" which reviews a popular biological explanation which assumes "biogenetic" superiority of development in European peoples as compared with non-European peoples. The chapter reviews the history of scholarly disputes, including a contrast of the paradigms of Plato and Herodotus, a discussion of science versus history, Descartes's ideas about "true" science. The ideas of John Stuart Mill, Wilhelm Dilthy and Wilhelm Wundt are presented with regard to theories of psychology and culture. The chapter ends with a brief discussion of the early stages of the "second psychology" and its various branches, still fragmented and not yet integrated in comparison to the dominant psychological paradigm. The author primes the reader for a discussion of his personal relationship to the competing paradigms and their contribution to understanding the relationship of culture to mind which are shared in the chapters to come.

\section{Cross-Cultural Investigations}

In Chapter Two, the author traces the major attempts to apply the strategy of cross-cultural research. He identifies its problems and accomplishments. Chapter topics include perceptual processes and culture, intelligence and culture, and memory and culture. Some of the significant research with primitive peoples that highlight their extraordinary gifts, particularly their perception and memory, are highlighted.

\section{Cognitive Development, Culture, and Schooling}

Chapter Three focuses on cognitive development and the standard methodologies that may be improved by conducting multidisciplinary research on cognitive development. This process begins by studying people at the point of their own everyday experiences. While the approach holds the potential of reforming experimental methodology and bringing about a coalition of social scientists-anthropologists, sociologists, and linguists - there are clearly recognizable problems. Aside from "unbridgeable gaps" between the scientists' knowl- 
edge of what they know how to experiment on and the natives' descriptions of native tasks, the possibility of scientists being forced to assume, theoretically, that a common universal core of human nature exists is also problematic. Cole shares with the reader his experiences in Liberia that drew him into cross-cultural research. The chapter also includes an important discussion of a challenge to Piaget-inspired cross-cultural research on cognitive development. Cole concludes the chapter by giving his summation of research on cultural differences in cognitive development. Respectfully disagreeing with the research of Berry in Africa, Cole finds no compelling evidence for the the presence of cultural differences in cognitive style.

\section{From Cross-Cultural Psychology to the Second Psychology}

Chapter Four discusses the author's search for an alternative formulation of the issues and their resolution. Cole presents the idea that the two psychologies after which the chapter is titled, need to be rethought. "As a first step," he says, "toward reformulating a more adequate approach to the relations between mind and culture we need to recognize that psychology (like all social sciences) is a sharply divided discipline" (p. 99). Other topics include a discussion of the growth of interest, in recent decades, in literature-substantiated thinking toward the formation of a cultural psychology. Cole returns to his earlier mentioned ideas proposing a cultural-historical approach. He shares with the reader the steps of his education, research, and reading that led him to his present ideas about the importance of a cultural-historical approach. He also discusses the key role of his mentor, Alexander Lucia, in his development. Cole discusses three premises or basic principles of cultural-historical psychology and closes the chapter with a discussion of the fundamental aspects of creating a broad theoretical framework that unites the two psychologies.

\section{Putting Culture in the Middle}

In Chapter Five, Cole begins to elaborate upon a concept of culture and mediation, which retains the key elements of the Russian approach. He proposes a concept of culture "that while consistent with their views, at the same time, works in a complimentary way with contemporary cultural anthropological approaches and cognitive psychological perspectives" (p. 116). Cole enters into the reconstruction of the cultural-historical approach to human development. He presents a critical update of the narrative of psychological development in the phylogenetic and cultural-historical arenas. Cole also includes a discussion of artifact as both material object and ideal. By this, Cole follows the dual material/conceptual nature of artifacts presented by the Russian philosopher Ilyenkov, who formulated the view that the form of artifacts is both material and transcendent because artifacts are both manufactured and put 
into use. Cole explains that an artifact acquires significance in the ideal, which is beyond the physical substance of the artifact. This chapter also includes a discussion of how "context" "surrounds" the learner or child. Activity and practice are juxtaposed with concepts of context and situation. The chapter closes with a summary of the view of culture which Cole had set forth in the chapter.

\section{Phylogeny and Cultural History}

Chapter Six reexamines the question of culture's role in human origins and historical change. Topics include phylogenetic history, tools and bodily change, apes, humans, and key transformations that produced modern Homo Sapiens. Cole also discusses some of the complex relations between human biology and culture. He includes a section on heterogeneity and hierarchy in the context of his cultural-historical level.

\section{A Cultural Approach to Ontogeny}

In Chapter Seven, the author presents several cultural approaches to ontogenetic development, which he explores from his own cultural-historical perspective. Topics include embryogenesis, language experience deprivation, language acquisition, mathematics, and a very brief discussion of a "sequence of events" learning program. Also included is an interesting discussion called "The Intertwining of the Natural and Cultural Lines Reconsidered."

The Cognitive Analysis of Behavior in Context

In Chapter Eight, Cole addresses the methodological problem of how to ground one's psychological analyzes in the culturally organized activities of everyday life. The chapter includes ones of Cole's cross-cultural projects on literacy with the Vai peoples of northwestern Liberia. The central point is that it is possible to create experimental tasks that are modeled on everyday practices. Moreover, Cole presents evidence that effective analysis of cognitive processes outside formal experimental tasks can be carried out when everyday practices are subject to sufficient constraints.

Creating Model Activity Systems; a Multilevel Methodology for Cultural Psychology; and the Work in Context

Chapters Nine, Ten, and Eleven review and focus upon the work of Cole and his associates over the past 15 years. Chapter Nine presents his cultural mediational approach to teaching reading. His Question-Asking-Reading method of teaching children how to read utilizes the Vygotskian principle that sets the stage for complex mental processes (intrapsychological) within a child's mind. In Chapter Ten, Cole presents a new methodology wherein small cultural systems are created and studied over years in their own context. The heart of the 
chapter revolves around The Fifth Dimension Intervention Project, which is a powerful computer-based program of mediated activities. This approach provides an exciting reference point for exploring ideas and metaphors about artifacts, context, and exactly what culture is. In Chapter Eleven, Cole gives a summary of his current thinking about what makes the study of culture in mind difficult. He also presents his ideas about theory and research that hold potential to deepen our understanding.

This book provides an exceptionally lucid exposition of Michael Cole's ideas about why a cultural-historical approach to psychology is necessary. Clearly, he is a brilliant intellectual with extraordinary dedication, focus, creativity, and commitment. This book should prove valuable for the person who would like to better understand the history of developmenta! psychology and the cultural roots which "once were." The book also gives a clear view into the more anthropological aspects of research and interaction with people in more traditional cultures and societies. Further, the book gives key insights into how children leam and the role technology will play in leaming as well as in providing future insights into the complexities of the mind in culture.

Muhyiddin Shakoor Department of Counseling Education SUNY College at Brockport Brockport, NY 14420 